\title{
Crip Heroine or \\ Mainstream Mock? \\ - Negotiating the Performances of Lady Gaga
}

\section{Af Lise Dilling-Hansen}

\begin{abstract}
Crip Heroine or Mainstream Mock? Negotiating the Performances of Lady Gaga

Since rumors about Lady Gaga's undefinable sex - and later sexuality and gender - began to spread, queer issues have been a central part of the artist's performative work. Through Gaga's social work, the norm-deviating body has become a central element too. This has led a whole generation of fans to frame Gaga as a queer hero, helping them coming out, and as a crip idol who, with her body as an activist tool, mobilizes hundreds of other bodies to participate in a bodily democratizing campaign aiming at higher self-esteem. Building on data collected in online Lady Gaga fan forums as well as in public debates represented by articles from mass online media sites, this article investigates how the performances of Lady Gaga place her as a heroine to some, but at the same time produce heavy skepticism and criticism of the artist's intentions.
\end{abstract}

\section{KEYWORDS}

Lady Gaga, disability, crip hero, queer, popular culture.

Lise Dilling-Hansen is a PhD student in the Department of Aesthetics and Communication at Aarhus University. Her research explores the gender and body performances of Lady Gaga, the affective relation between Gaga and her fans, and the cultural negotiation work carried out by Lady Gaga's fans. 


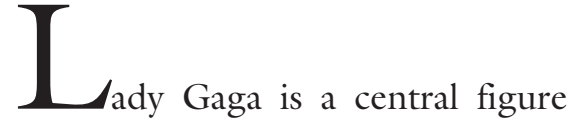
in today's mainstream culture. Yet while this is so, through her norm-deviating performances, she challenges the sex, gender, sexuality and bodily stereotypes of mainstream visual culture. While artists like Madonna used the music video as a channel with which to subvert cultural stereotypes, Gaga, more than any other artist, has mastered the use of social media and manages to mobilize her fans online. This article examines two questions arising out of Lady Gaga's mediated performances.

The first of these questions is how, or whether, Lady Gaga's sex, gender, sexuality and bodily representations challenge stereotypical ideals in the mainstream media? Firstly, by strongly supporting LGBT rights, and by integrating queerness - here understood as dealing with "non-normative forms of identity" (Corber \& Valocchi 2003: 1), representing a new "paradigm for thinking about sexuality" (Hall \& Jagose 2013: xvi), and creating a space to include those "whose bodies or sexual desires do not fit dominant standards of gender and/or sexuality" (Beemyn \& Eliason 1996: 5) - into her performance. Secondly, by performing a new signification of the disabled body in which Gaga crips ${ }^{1}$ the homogenized binaries of able/disabled, sexy/ ugly and normal/freak, thereby ultimately cripping the bodily hierarchy in popular culture.

The second question is how Gaga's norm-deviating bodily performances are negotiated online. The data for this discussion is mainly collected on the more than 20,000 member fan forum GagaDaily, consisting of ten selected threads from November and December 2013, and on the fan webpage Littlemonsters, consisting of the hundred latest (of December 2013) posts in the thread Body Revolution. This means that the main part of the negotiations presented in this article comes from fans of $\mathrm{La}^{-}$ dy Gaga and is thus not representative of a general public. The purpose of this is to show how the queer and crip performances of Gaga are received by the fans and to discuss to what extent Gaga manages to perform a queer and crip role model for the fans. These responses are predominantly positive towards Gaga's performances and the personal impacts they have on the lives of the fans. However, as some of the examples will show, the fan responses are not unequivocal and also reveal a resistance to some of the performativity of Gaga. In order to include some of the negotiations made outside the world of Gaga, the data also consists of articles from mass online media sites; Examiner, Life and style, Huffington post and The Guardian, to show how Gaga is received by part of the gay and disabled community, as well as by a general public.

This article will show how Gaga on the one hand is established as a spokesperson for queer identities and as a "crip hero", challenging the interpretation of disabled people as tragic by "a display of extraordinary physical strength and endurance, despite having an alleged deficiency" (Apelmo 2012: 40-41). On the other hand, how she is criticized for being a dubious role model who uses queer issues, face implants, crutches and wheelchairs for "shock value" and "exploitation," and for being too mainstream herself even as she celebrates deviation and triumphs over insecurities.

\section{QUEERING MAINSTREAM CULTURE}

A coherent notion of mainstream or $p o p u$ lar culture is impossible to reach and will inevitably be described in very broad terms. However, in order to place the performances of Lady Gaga as challenging of a mainstream popular culture, I will here adapt John Storey's definition of popular culture as a culture that is widely favored and is defined through its contradiction to 
high culture although not, at least not here, valued as neither more or less important (Storey 2012). My application of the term mainstream builds on Rosalind Gill's observations of how mainstream media representations are imbued by a post-feminist view (Gill 2007) where women - although depicted as equally sexual and powerful to men - still more or less are inscribed into the heterosexual matrix (Butler 1990: 208). Mainstream, thus, refers to a stereotypical notion of gender and sexuality. I do acknowledge, however, that the total of representations of women in popular culture is more complex than 'Lady Gaga and the rest'. With her high-heeled shoes, long hair, dresses, makeup and the fit, yet feminine body, Gaga is not the less mainstream artist of the music industry. However, her performed gender and sexual identity differs from that of most female artists today, which makes her an interesting phenomenon to study.

Only a year after Lady Gaga's artistic breakthrough in 2008, the media suddenly switched their focus from her musical success to her gender. After a performance at Glastonbury Festival in the summer of 2009, a very short dress caused a media storm because it supposedly showed something 'unexpected' between the artist's legs, leading the gossip industry to wonder what sex Gaga concealed under the dress. Speculations followed about Gaga's sexual preferences along with a general interest in her sexual identity. Although Gaga herself stated in an interview with Barbara Walters that she has female genitals and is sexually attracted to both men and women, the question was not settled there, as Gaga herself continued to raise it in her performances. On her Monster Ball Tour, she yelled out at each show "I have a pretty tremendous dick," and at the 2011 Video Music Awards, Gaga arrived as the male character Jo Calderone. In the video Telephone, Gaga is thrown into a prison cell by butch female prison guards. When Gaga is stripped, one of them says, "I told you she didn't have a dick". However, as Gaga's crotch is blurred in the video and remains out of view for everyone but the guards, the sex in question is still blurred for the public. A final example is Alejandro who with love lyrics from a woman to a man repeat the heteronormative pattern while a music video performs queer notions of sex, gender and sexuality. Sexual acts take place between Gaga and several 'stereotypically gay looking' men and the men are both taken from behind and sit on top of Gaga. This is far from reiterating heterosexual intercourse, and at the same time Gaga's female, almost animalistic, teeth-baring, sexuality is very aggressive and rough, and certainly not heteronormative. When she is later 'taken' by the men in what seems to be a gang rape, she wears an arrow pointed toward her crotch and soon rolls over onto one of the men and returns the sexual action: what is usually considered an act with no pleasure for the woman seems to excite Gaga most of all. Rather than expressing a (female) desire to become equal to men, the performances deconstruct the binary systems of sexes, genders and sexualities normally represented in popular culture.

Ambiguous play with sex, gender and sexuality thus became a central element of Lady Gaga's performances in which she disrupts the dominating discourse in popular culture. These disruptions led queer-theorist Jack Halberstam to define the term $G a$ ga feminism to mean a new kind of feminism representing "a loud voice for different arrangements of gender, sexuality, visibility, and desire" (Halberstam 2012a: xii). Halberstam has argued that this feminism above all is "concerned with reconfiguring the meaning of sex and gender in ways that may favor heterosexual women in particular" (Ibid: 82) and that it can be read as representing "a potent avenue of alternative femininity" (Halberstam 2012b). In a reading of Telephone, Halberstam states that the video is about male castration, with girl- 
friends running off together in a femme liberation (Halberstam 2010a), stating also that it can be read as a sort of lesbian relationship between Gaga and Beyoncé (Halberstam 2013). Halberstam's queer readings thus suggest that Gaga feminism represents (and favors) a female, non-heterosexual identity. However, although Gaga's world is 'imbued by a queer view' and almost practices what examples of queer theory preach, Lady Gaga can be read differently than as a "sort of lesbian" queer. Following Chris Beasley's idea that heterosexuality is the elephant in the queer-theoretical room - a room in which "robust conceptions of hetero-pleasure and its possibilities have not been sustained" (Beasley 2010: 206) - and given queer theory's promise to represent all deviating forms of sex, gender and sexuality, I suggest that rather than performing a bisexual or lesbian queer sexual identity, Lady Gaga can fruitfully be read as a queer heterosexual identity deviating from the heterosexual matrix (Butler 1990: 208), and thus representing a possibly even more queer construction in mainstream culture; the hetero-queer.

Whatever labels are used to describe Lady Gaga, queer issues continued to constitute a significant part of her performative work, becoming even more explicit with her 2010 appeal against the unwritten Don't ask, don't tell policy of the American military and with her lyrics to Born This Way early in 2011:

No matter gay, straight, or bi

Lesbian, transgendered life

I'm on the right track baby

I was born to survive

No matter black, white or beige

Chola or orient made"2

\section{QUEER HERO?}

This queer-representation work has clearly influenced Gaga's audience, as shown by the number of fans who self-identify as queer $^{3}$ and by the fans' emphasis on queer issues as important factors in this fandom, where Gaga is generally seen as understanding and/or a part of the LGBT community (unlike, for instance, Britney Spears, who was heavily criticized on the fan forum GagaDaily for stereotyping and failing to know her gay fans when she called them “somewhat girls, so it's so inspiring to do stuff that they like to hear, like the cool 'in' stuff"). Queer issues are frequently addressed on GagaDaily. Many fans pay tribute to the impact Lady Gaga has had on their private lives and on how, as individuals, they have dealt with their own queer identity. Numerous testimonials like "She made me accept that I'm gay and that being different is great" and "She gave me the strength to come out as gay and later transgender" are to be found there. One fan tells the story of how his life changed when he discovered Gaga. Bullied in school and ashamed of being bisexual, he had attempted suicide twice; when he found out that Gaga herself was bisexual and had been bullied, and that she fought for LGBT rights, he found new hope. A Gaga concert "changed his life and he became braver", and in 2011 he "started taking action to fight against discrimination based on Sexual Orientation and Gender Identity" (and as at November 28, 2013 was still doing so).

The fact that queerness is part of Lady Gaga's performative work seems to have supported a whole generation of fans in their coming out, even to have changed their lives to the point where they can begin to take action themselves. However, the artist's queer aspect is not uncomplicated. One issue is that the focus on $\operatorname{LGBT}(\mathrm{Q})$ rights has affected not just the way Gaga is interpreted, but also the way the fans are seen, for instance: "People think I'm gay just because I like Lady Gaga", "When BTW came out, I started to get bullied because it was 'gay' to like Gaga", and "Many people don't want to associate themselves 
with other that so loudly advocate LGBT rights for fear that they will be bullied". These stereotyping issues also affect some queer fans: "Well, a lot get annoyed since Gaga claims to be champion for LGBTQ rights, but she usually only mentions the $\mathrm{G}$ part of it", and "The gays hate that she became stereotypically gay". Further issues are that, outside her performance, Gaga does not live a life that is queer enough: "There's a whole Tumblr for gays against Gaga. I think a lot of them find it hard to have someone who, although claiming to be bisexual, lives a generally heterosexual life". Frequently mentioned in the online negotiations is that some interpreters both queer and non-queer - see Gaga's focus on $\operatorname{LGBT}(\mathrm{Q})$ rights as a commercial strategy: "Some gays have this thing where they all decided she's... using them... * rolls her eyes*". Finally, the fact that Gaga was not the first artist to speak out for $\mathrm{LBGT}(\mathrm{Q})$ rights is an issue for some, who argue that even if Gaga is seen as a queer hero for the young generation, "the rest of the community, especially the older gays, know that Madonna paved the way for mainstream artists to discuss LGBT issues in popular music".

Via her challenging of the stereotypes of sex, gender, and sexuality lingering in mainstream culture, and her public awareness of the LGBT community, Lady Gaga has been established as a queer hero for many of her fans for whom she provides personal support in their own queer identity struggles, and even life changes and savings for some fans. However, the online debates also revealed a complexity in negative negotiation work by the fans, who for various reasons placed Gaga as 'wannabe queer', 'stereotypical queer', and 'exploiting queer' rather than a hero.

\section{CRIPPING MAINSTREAM CULTURE}

In 2009 the artist Lady Gaga released her sixth music video, Paparazzi. Telling the story of an extremely rich and famous Gaga, the video deals with living with popularity and the pressure of being hunted by the paparazzi. However, the video also critiques the pressure exerted by popular culture to look perfect. In the Paparazzi video, Gaga "hits rock bottom", according to the paparazzi, as soon as she lies twisted on the ground after a fall from a great height, thus becoming (momentarily) disabled. The star is "over" now that her body suddenly does not belong in the industry of fame and fortune - in the mainstream visual media. Gaga, however, proves the mass media wrong and returns with a powerful prosthetic body, performing with a broken neck in a wheelchair and dancing on her crutches in a cyborg-like gold outfit, becoming the "new It girl".

Bodily norm-deviating, like queerness, is a central constituent of Gaga's performative work, as in the twisted spine in the Bad Romance video, the face implants in the Born This Way video, and two live performances I shall return to later in which Gaga performs once bald and once in a wheelchair. Before revisiting these performances and the question of how the norm-deviations are negotiated, I wish to argue that these performances point to a new signification of disability and of the disabled body, categories, which in the mainstream visual media constitute ugliness.

Robert McRuer in his book, Crip Theory (2006), emphasizes the Oxford English Dictionary definition of able-bodiedness "soundness of health; ability to work; robustness" (McRuer 2006: 7). Here a disabled body is defined as unhealthy and incapable of working. This negative evaluation of the disabled body as defective and unproductive in society can be linked to the concept of docile bodies - a concept which, through the institutions of society, has created a hierarchy in which bodies were "subjected, used, transformed and improved" (Foucault 1975: 136) by the manipulating power of observation, normaliz- 
ing judgment and examination (Ibid: 170). The concept of docile bodies has shaped the interpretation of bodies into our times. Towards the end of the twentieth century, the medical interpretation of disability was replaced by the social model, based on the social constructivist approach (Richardson 2010: 168-169). This model of disability focused on a distinction between impairment, referring to physical and mental dysfunctions, and disability, the cultural interpretation of this impairment (Apelmo 2012: 50; Tregaskis 2002: 458).

Drawing on the constructivist stance in the social model of disability, the critical model of disability studies pushes the antiessentialist approach even further, and questions the dichotomy between the categories of abled and disabled bodies. In so doing it "challenges every one of us to rethink the relations between disabled and non-disabled designations" (Shildrick 2012: 30). The critical model of disability studies thus advocates new ways of thinking about the category of disability as a fluid concept in the same sense as the notion of queer applied in this article. Where queering disrupts binaries such as woman/man, homo/hetero, and unnatural/natural desire, cripping (also) challenges, for instance, those of attractive/repulsive, and physically able/disable of taking part in society. Both the acts of queering and cripping hold the potential, firstly, for an inclusion of the acts/bodies/sexualities normally excluded from the mainstream culture and thus for a disruption of the hierarchy of the social acceptable and 'normal' vs. the 'outcast' of society. Secondly, queering and cripping blur the categories of queer and crip, hence challenging the existence of fixed categories. Robert McRuer suggests a "coming out crip" movement to acknowledge that we are all somehow disabled, and that being crip holds a positive power to change the compulsoriness of the collective aim for being able - for being the same (McRuer 2006: 2). This critical approach to the field of disability is relevant when dealing with a phenomenon like Lady Gaga, since her performances crip the category of 'normal', and thus exemplify the fluidity of the category of disabled, which enables a new signification of the term disability and places us all as disabled.

Niall Richardson argues that it is "too naive to think that 'able-ism' is simply about the functionalism of the body; it is also concerned with the sexual attractiveness of the body" (Richardson 2010: 172). Disability is often contrasted with beauty and sexiness and "is a signifier of ugliness, tragedy, asexuality, invalidity and frailty" (Rogers 2010: 64). Building on Eva K. Sedgwick's rethinking of Gayle Rubin's sexual hierarchy, which replaced binaries such as homosexuality vs. heterosexuality with for instance persons with a small vs. a bigger sexual need, Jack Halberstam claims that we need to rethink the organizing logic of the sexual hierarchy. Social categories such as the ugly - which "in other words is the unattractive (woman), the lonely and the socially difficult" - are an example of the social outsider low down in the sexual and social hierarchy (Halberstam 2010b). In society today, where the media attaches such importance to beauty, coolness and sexiness, and where we are "obsessed with the body" and its regulation and discipline (Richardson 2010: 1), being 'ugly' can then actually be considered a disability. ${ }^{4}$ Particularly in the field of popular and consumer culture where looks are a commodity, being 'ugly' (meaning: not fulfilling the stereotypical ideal of beauty and sexiness) places a person at the bottom of the sexual and social hierarchy or simply excludes them from it. With the theoretical framework of critical disability studies and the notion of 'ugliness' and 'unattractiveness' as disabilities in popular culture, let's return to the performances of Gaga.

The opening lines in Lady Gaga's hit Paparazzi are: "We are the crowd. We're cocoming out." What seems to be the same 
we later shout out, "We're plastic, but we still have fun." The crowd, or the young, of the Gaga generation are more plastic than ever and recently they are beginning to come out flashing the partial artificiality of their bodies. At the same time they are coming out crip, they are emphasizing that a body without certain 'beauty tools' in mainstream consumer culture is just as lost as 'crippled Gaga' without her crutches. The beauty discourse in mainstream media, Garland-Thomson argues, “terms women's unmodified bodies as unnatural and abnormal, while casting surgically altered bodies as normal and natural" (Garland-Thomson 2008: 27). The made-up, retouched, trained, dieted and generally disciplined body is the only 'natural' body in this culture, and as female rapper Nicki Minaj stated in an interview, "Every female in this game wears wigs". According to Tobin Siebers, tools like stairs, elevators, escalators, washing-machines, eggbeaters and chainsaws - appliances which help ablebodied people to perform tasks - are viewed as "natural extensions of the body, and no one thinks twice about using them". Tools used by disabled people to perform tasks in their daily lives, on the other hand, are seen as "expensive additions, unnecessary accommodations, and a burden on society" (Siebers 2009: 31). The tools that secure the right look for the industry of popular culture have also become accepted as 'natural' extensions of the body - they have become part of the game. There are thus unwritten rules in modern society for what 'tools' are acceptable in mainstream culture and 'beauty tools' are required to be used to give the artist a look that is closer to the ideal. This exemplifies why the category of the able body also needs to be questioned. The sick body with an eating disorder can be seen as sexy and healthy, bound feet were seen as sexy in China until the twentieth century despite causing impairments for the women, and "wearing a hearing aid is seen as much more disabling than wearing glasses, although both serve to amplify a deficient sense" (Davis 1997: 54). That is, the bodies that are interpreted as 'normal,' in any given time, may very well be sick or disabled in a different context. The performances of Gaga are representing a body, which is situated as 'abnormal' in our time, but which suggest a possible future in which the disabled body has gained a new significance. Lennard Davis's idea of dismodernism captures a world in which the ideal is not a "hypostatization of the normal (that is, dominant) subject", but instead aims to create "a new category based on the partial, incomplete subject". The subject of dismodernism is by definition disabled, and can only be "completed by technology and by interventions" (Davis 2002: 30). This means that every subject is set free from the demand for 'natural' perfection, as it is recognized that we all are reliant on technologies to varying degrees. The dismodernist way of thinking is closely linked to the cripping potential of Lady Gaga's performances. In integrating technologies that are normally associated with a disabled body, Gaga states, first, that she herself needs 'tools' as a performing artist in mainstream popular culture, and secondly, that a body that is incomplete without technologies is not to be considered incapable of taking part in normative social participation. On the contrary, such a body becomes the "new It body": it makes disabledness more visible on all bodies, and it crips the disabled body out of the category of disableism.

Gaga's hair received little media attention (although her many wigs make it very clear that she too is "part of the game") until the 'beauty tools' took the form of a bald cap, when Gaga performed the song Hair, without hair, on the Paul O'Grady show. Reactions in YouTube comments on the video are mostly extremely positive, expressing that Gaga serves as an inspiration for her fans to be brave and to believe that 
they are beautiful even if they do not live up to the stereotypical ideal of consumer culture. Performing without hair, Lady Gaga enacts a body aesthetic that is normally excluded from the field of fame and beauty. She exemplifies how people without hair can be part of this system. Singing "I'll die living just as free as my hair/I've had enough, I'm not a freak", Gaga makes it clear that it is time to criticize the construction of what is considered unhealthy, disabled, unsexy and pathological in the dominant beauty discourse. Gaga's bald performance, in which she physically 'disables her' look, can be read as a cripping of the sexual and social hierarchy, of the docility of bodies in modern culture and of the unwritten rules for body-modification tools. The artist has stepped into a dismodernist world. She is stating that if we recognize that we are all dependent on technologies, we can all be free, as free as our hair.

\section{MOCK OR ROLE MODEL?}

In 2011 Lady Gaga gave another remarkable live performance in You and $I$ as a black-widow mermaid in a wheelchair. The wheelchair caused such a stir that eggs were thrown at Gaga at a public appearance later the same day. The performance also started a vibrant debate online on whether using a wheelchair in a performative act should be considered offensive to people who have to use a wheelchair in their daily lives. The debate split people into two camps. One camp defended Gaga and her use of the wheelchair among the 160 online comments on the Huffington Post edition of the story (Von Glinow 2011) with statements like: "Plenty of people live everyday in a chair. She is depicting that. Why should she be egged?", and "As a wheelchair user myself, I am not the least bit offended by Lady Gaga or her wheelchair[... ] I AM offended by those people who would 'speak FOR the disabled' by throwing eggs". The other group took a different stance. The Roman Reed Foundation posted a message to Gaga on Twitter saying, "Dear @ladygaga how about using your celebrity status 2 try 2 get us out of wheelchairs. Instead of cruising one. Cool?" and the foundation Life Rolls On wrote, "Since this isn't the first time she has used a wheelchair in her performances, I invite her to learn more about the 5.6 million Americans who live with paralysis. They, like me, unfortunately, don't use a wheelchair for shock value". These messages were backed up with comments like: "I'm handicapped and it's hard enough to live this way w/o someone pretending (mocking?) to be handicapped just for 'shock' value", and "Lady Gaga is a freak and by portraying herself in a wheelchair, she makes people with disability be seen as freaks like her".

Although the performances in which Gaga uses a wheelchair can be interpreted as a positive move to include those who are normally outside the social and sexual structure in consumer culture, these performances seemed to provoke - and divide people to a much greater degree than the bald performance. One explanation for this is that baldness is not defined as a disability condition, whereas "the whole spectrum of disability is often signified by the wheelchair user" (McDougall 2006: 396).

Lady Gaga is, with her performances, exemplifying how the disabled body can figure in the dominant beauty discourse. Still, the fact the wheelchair wasn't used out of need caused a lot of antipathy, since Gaga, unlike 'real' wheelchair users, could get up and walk away when the performance is done, which, for them, made her a dubious role model. 5

By including the disabled body in mainstream culture and at the same time cripping the abled body, Gaga seems to stand out as a crip hero - at least for some. One example of a crip hero is Aimee Mullins, the model, professional athlete, and actress. Although role models like Mullins do in- 
spire people, she is also "very far away from the everyday life of people living with disabilities" (Apelmo 2012: 40-41). Lady Gaga is to a certain extent comparable with Aimee Mullins. Even though she is setting a good example, Gaga is still very far from being a chemo patient or suffering from paraplegia. Elina Vaahtera argues that performing in a wheelchair does not "change any hegemonic meaning of able-bodiedness" (Vaahtera 2012: 85), because as Gaga is only pretending, her performances can never be truly subversive. However, even though the artist can in fact stop being 'disabled' whenever she wants, the performances of Gaga still hold the power to subvert the homogenized structure of the dominant social and bodily discourse in mainstream popular culture. As stated in the positive comments on the live performances of Hair and You and I, Gaga can be seen as an inspiration, challenging the stereotypical beauty ideal and representing the disabled body as a desirable body. By stating that the body can still be sexy and powerful without hair or in a wheelchair, Gaga crips the bodily hierarchy and suggests its redefinition. She thus both includes body representations normally excluded in popular culture, and she emphasizes the fluidity of the category of disableism.

After a hip surgery at the beginning of 2013 Gaga had a 24 carat gold designermade wheelchair created for her, and photos of the new look, by fashion photographer Terry Richardson, were shared online shortly after. Hence did Gaga now appear as a more 'authentic' wheelchair user, but she also established the wheelchair as tool, which can be used as a fashion statement. In spite of this, Gaga was still accused of using the wheelchair as a "publicity stunt" and was also criticized for choosing a designer wheelchair and thus "glamorize disabilities" (Kornowski 2013). Being a 'glamorous disabled' Gaga does suggest an interpretation of the disabled body as po- tentially beneficial in the world of fashion, but she also here risks placing herself as the crip hero, since a very expensive wheelchair and a photo shot by Terry Richardson is out of reach for most people.

Lady Gaga has shocked the world with many outrageous looks in her music videos, fashion photos and live performances. In spite of these very provocative stylistic expressions, the look that seemed to shock the world (or at least the press) the most was her weight gain. After a show in Amsterdam 2012 the media exploded with pictures of her "meatier" or simply "fat" body, depending on the media tone. In mainstream popular culture, body fat is considered disgusting. 6 It is, according to Richardson, one of the most-feared conditions of life and is, in its abject form, to be understood as something "hanging out" of the body, a signal of "sloppiness" and of "letting it all go," indicating a loss of control (Richardson 2010: 75-81). Although Gaga has performed so many times as a monster or an alien, these looks caused far less media stir than the extra pounds on her body. As Monica in Friends and Julia Roberts in America's Sweethearts are bearable and funny to watch because they are not really fat, but only wearing a fat suit (Ibid: 84), Lady Gaga is quite safe to watch as a monster or an alien. Although the visual aesthetics may be disturbing, the performances are watched in the knowledge that the artist is wearing a monster or alien 'suit'. Naked flesh shown on stage, however, is something cannot be taken off when the show is over. Appearing in a body that has done what is mostly forbidden in popular culture - putting on weight, and doing it fast - Gaga is performing a body that is out of control, a body that is out of order. The rapidly weight-gaining body fulfills fears of getting fat by emphasizing how fast a perfectly fit, skinny body can 'fall apart'. This is, therefore, interpreted as the most disturbing version of Gaga the public has yet seen. The 'fat' body is an anti-docile 
body, refusing to be subjected, used, transformed or improved by society's manipulating power. It is thus a body that threatens the structure of society. The result is a media storm, telling the body to reoccupy its hierarchical place. The media stir over Gaga's 'fat' body is another example of the unwritten rules on body modifications. Appearing with bones seeming to jut from her skin, as in the Born This Way video, may have been read as weird, but it caused almost no media stir. A normal-weight body, however, is unacceptable.

Moving towards a conclusion, I will discuss how Lady Gaga used the media stir over her weight gain to mobilize others in a bodily democratizing campaign via social media and how this was negotiated on GagaDaily and on the fan page Littlemonsters.

\section{A Body Revolution?}

In the fall of 2012, Lady Gaga's visible weight gain became a hot topic in the media and a wealth of harsh comments demeaned Gaga's body. This led her to launch a Body Revolution, which she put to work by posting four pictures of herself wearing only underwear on the fan page Littlemonsters. The pictures were tagged "Bulimia and anorexia since I was 15", "But today I join the BODY REVOLUTION", "To inspire bravery" and "and BREED some m\$therf* cking COMPASSION." Gaga then encouraged everyone to post pictures of themselves and their alleged flaws, saying, "Now that the body revolution has begun, be brave and post a photo of you that celebrates your triumph over insecurities". The fan page exploded with self-portraits, posts, and highly emotional communications from fans, with hundreds and hundreds of comments establishing Gaga as a courageous leader and an inspiration, helping, teaching and bonding on a "deep personal level" with her fans, saying things like the following:
"Ur the definition of beautiful, and the media is so fucked up its crazy", "I did it for $\mathrm{u}$ momma. $\mathrm{U}$ made me brave and helped me overcome the hardest time of my life", “I can't stop crying. Gaga I'm battling the same thing right now this is making me strong", "This is my story, I wanna share it with all of you", "You give us the strength to take the parts we are supposed to be ashamed of and make them into our pride", "So proud of you for being brave enough to show your true self. You inspire us all to do the same", and "I get it as so many of us do. I really do get it and I love you soooo much for being this brave to raise awareness." For these fans there is no doubt that Gaga is using her 'deviating' body to help them feel better about themselves.

The pictures uploaded by the fans depicted bodies or body parts which all had in common that they did not live up to the mainstream image of the ideal. Among the 'non-perfect' depictions were skin diseases, scars, acne, anorexia, (female) curves, cancer treatment, achondroplasty, and missing body parts. The Body Revolution thus represented a much broader and more varied selection of bodies set in a positive framework than those visible in the mainstream media. Adopting the idea of the norm-deviating or 'ugly' body as a new signification for the disabled body, the Body Revolution was meant to encourage people to come out crip - and with great success.

With the Body Revolution, Lady Gaga had created a tangible space in which her fans could find inspiration and strength to change their self-image. Gaga used social media (not only Littlemonsters, but also Twitter, Facebook and Instagram, which are connected to the fan page) as a tool through which, in the tradition of the performative speech act, she could do things with words (Austin 1962) by proclaiming that, in clicking 'post', she would inspire bravery and breed compassion. The power of the visual aspect of the social media en- 
abled Gaga to "do things" not only with words, but also with the body. Gaga's body thus became an activist tool, mobilizing hundreds of bodies to participate in this bodily democratizing campaign. In launching the campaign, Lady Gaga was offering the fans a platform from which the fans could perform, cite and reiterate (Butler $1990,1993)$ an alternative representation and idea of beauty to that provided in mainstream culture.

Looking at all the 2012 responses to Gaga's Body Revolution - including skeptical criticism like this sarcastic comment from the Guardian: "Oh gosh, thanks, Gaga! And here I was planning to hate myself. Now I'm really in the mood to buy some Lady Gaga merchandise, after all, it comes packaged with free self-esteem!" (Doyle 2012) - it seems fair to conclude that the artist managed to serve as a role model and a hero for thousands of people. However, a revisit a-year-and-a-bit later illustrates the dubiousness of Gaga's position as perfect role model. Of the 100 most recent posts in December 2013, only 6 per cent could be categorized as citing the Body Revolution as it was in its beginning. Rather than "celebrating triumphs over insecurities", more than three-quarters of these posts consisted of before/after pictures in which a 'Body Revolution' had taken place and had transformed the body in question into a slimmer, fitter, less geeky, more masculine and/or sexier body. Fifteen per cent of the posts depicted bodies, which had already reached their goals, showing off six-packs, faces full of confidence, and thin bodies. The last couple of posts celebrated the body of Lady Gaga and its perfection.

In the year that had passed since the launch of the Body Revolution, the body of Lady Gaga herself has also undergone a remarkable change. Although the artist claimed to be confident about her weight, saying her boyfriend "preferred her curvier" at the time of the revolution launch,
Gaga had lost a lot of weight when she returned to the spotlight after a hip injury in summer 2013. And, even with no provable direct link between Gaga's weight loss and the change of focus in the Body Revolution, some of the newer Body Revolution posts reveal some coherence between the two developments. One fan writes on GagaDaily: "I'm fatter than she is now. I kind of am like she was during BTWB when everybody called her FAT. To be honest, I was sad because of that. It means that I'm really fat". Another fan uploaded a picture on Littlemonsters from the fall edition of $V$ Magazine in which Gaga posed naked, revealing a very thin body with no belly fat and her ribs sticking out. The fan attached a text that expressed her shame at not having managed to lose more weight: "I was so depressed about the fact that I couldn't reach $10 \mathrm{~kg}$ less[... ] Sometimes I was eating bad things and felt guilty". The title of this fan's post is Body Revolution keeps going! and since posts with the hashtag \#Body Revolution are still frequently posted online, the fan is of course right in this statement, but the 'manifesto' of the revolution seem to have changed or at least to have been highly negotiated. Although the majority of the posts show a different interpretation of the Body Revolution to that presented in September 2012, many of the fans on Littlemonsters still advocate the original revolution, saying things like: "You CAN change IF you want to, but you don't have to!", "You are just missing the point and spreading the wrong message", and "Body Revolution was never about changing yourself... it was about accepting yourself as you are". Other fans are renegotiating the Body Revolution, saying things like: “Actually, I thought Body Revolution was about knowing your imperfections and trying to correct them and making yourself better" and "How I see it Body Revolution is all about being happy with your body. Well as she wasn't happy she changes it to be happy, that too is Body Revolution". 
Here the fans are arguing that the Body Revolution means change and transformation of the body until one is satisfied. One fan even uses the transformation of the body of Lady Gaga to support this interpretation of the Body Revolution: "Lady Gaga herself had a body revolution. She started gaining weight and after her surgery she's in better shape than ever!"

As these various responses to the Body Revolution have shown, the campaign was and still is extremely popular. However, in spite of claiming that she (and her boyfriend) felt good about her weight, Gaga responded in fact to the public 'fat shaming' by losing weight. This influenced the fans' interpretation of the Body Revolution and of how it should be carried out. Jointly with the media coverage of her weight gain, Gaga reported that she was "dieting right now because I gained 25 pounds" and that she did not feel ashamed of the weight gain "because I have to be on such a strict diet constantly" (Chang 2013). These statements indicate a set of unwritten rules, controlling the body of a person in the popular cultural industry; one necessarily loses weight after a weight gain, and one has to be on a strict diet constantly. After her weight loss Gaga distanced herself from her 'former' body: "I lost everything that I love. I was in a wheelchair for six months. I did a lot of drugs and took a lot of pills" and reported that she mostly loved her new album "because it helped me to lose 30 pounds" (Waldholz 2013). The less thin and crippled body is thus situated as a body temporarily out of order linked with a state of general unhappiness, whereas the regain of the thin and able body signifies a redressing of the balance. Many of the fans reportedly benefitted greatly from Gaga's body revolution, however, the constraints of being an idol in mainstream culture seem to clash with trying to subvert ideals of this culture. At least the limits for how much subversive work the artist in question can do without losing her status as a desirable idol seems to be narrow.

\section{CONCLUSION}

Lady Gaga has, by including queer identity and sexuality into mainstream culture and by being a spokesperson for the LGBT community established herself as a queer hero for many of her fans. However, the online debates investigated also showed that Gaga's lack of being 'queer enough' created negative interpretations by the fans, who for various reasons placed Gaga as 'wannabe queer', 'stereotypical queer', and 'exploiting queer' rather than a hero. With her crip representational performances, Gaga also managed to show how a normdeviating body can be integrated into mainstream popular culture and how, in a culture where 'ugliness' and 'unattractiveness' can be interpreted as a disability, we all need 'tools' to be 'able', and hence she crips the category of disabled. This established Gaga as a crip heroine for many, both fans and people outside the fan community, but also caused a massive critique of her 'exploitation' of the 'real' disabled people because, like with the queer issues, she was not crip enough, according to her critics, to represent a crip body.

The mass media's reaction to the weight gain of Gaga emphasized how this particular body is seen as an anti-docile and thereby threatening body. The fan responses to the Body Revolution, however, underlined how much an idol who encourages and embraces 'non-normal' bodies is needed. Still, the fans' responses also revealed a central dilemma, which artists of the mainstream popular culture face when trying to subvert dominant discourses. On one hand, Gaga has to be careful not to deviate too much from the system of mainstream in order to remain recognizable and thus maintain a powerful position of influence. On the other hand, she risks being deemed inauthentic and exploitative of the people 
and bodies she tries to include in mainstream culture, if she is not accepted as part of them. The task of doing subversive work in mainstream culture is difficult to fulfill and although it seems most obvious to conclude that one can never be truly subversive in this culture, Lady Gaga might just be the artist who has found a perfect balance from which she is capable of maintaining her position in and at the same time subverting the system of mainstream popular culture.

\section{Notes}

1. 'Cripping' builds on the verb 'queering' and is representing a "form of resistance to cultural homogenization", subverting and redefining the dominant structure of the bodily hierarchy as it is (McRuer 2006: 33).

2 . This binary disruption is not altogether unproblematic, since bringing in more categories is not necessarily anti-essentialist and cannot, therefore, be interpreted as completely queer.

3 . The results of a poll on the fan forum GagaDaily in November 2013, asking "What sexuality do you fall under?" showed that only 12 per cent of fans defined themselves as heterosexual (other options were homosexual, bisexual, asexual and pansexual). This cannot of course be seen as representative for the entire Gaga fan community, but it gives an impression of the spreading of sexualities in Gaga fandom.

4. It is worth mentioning that the ugly laws, created in 1867 and spread all over the US - stating that "any person who is diseased, maimed, mutilated, or in any way deformed, so as to be an unsightly or disgusting object" should not been seen in public (Schweik 2009) - established a link between disability and 'ugliness' long before Lady Gaga.

5. The performances in question took place before Lady Gaga had hip surgery and was confined to a wheelchair in 'real' life.

6. Of course, with the reservation that some body fat is not only acceptable but demanded (e.g. breast fat and some fat on the bottom).

\section{REFERENCES}

- Apelmo, Elisabet (2012): Crip Heroes and Social Change, in: Lambda Nordica 17/1-2

- Austin, John L. (1962): How to do Things with

Words. Oxford University Press, Oxford.

- Beasley, Chris (2010): The Elephant in the

Room: Heterosexuality in Critical Gender/Sexuality Studies, in: NORA - Nordic Journal of Feminist and Gender Research, 18/3

- Beemyn, Brett \& Eliason, Mickey (1996): Introduction to Issues of Identity, in: Brett Beemyn \& Mickey Eliason (eds.): Queer Studies: A Lesbian, Gay, Bisexual, and Transgender Anthology. New York University Press, New York.

- Butler, Judith (1990) Gender Trouble: Feminism and the Subversion of Identity. Routledge, New York.

- Butler, Judith (1993): Bodies That Matter: On the Discursive Limits of 'Sex'. Routledge, New York. - Chang, Samantha (2013): Lady Gaga's Incredible 25-pound Weight Loss: Her Diet and Workout Secrets. Accessed 17/3 2014 on http://www.examiner.com/article/months-after-25-pound-weightgain-lady-gaga-flaunts-dramatic-weight-loss - Corber, Robert J. \&Valocchi, Stephen (2003): Introduction, in: Robert J. Corber \& Stephen Valocchi (eds.): Queer Studies: An Interdisciplinary Reader. Blackwell Publishing, Massachusetts.

- Davis, Lennard (1997): Nude Venuses, Medusa's Body, and Phantom Limbs: Disability and Visuality, in David T. Mitchell Sharon L. Snyder (eds.): The Body and Physical Difference: Discourses of Disability. University of Michigan, Ann Arbor.

- Davis, Lennard (2002): Bending Over Backwards. New York University Press, New York.

- Doyle, Sady (2012): Lady Gaga's 'body revolution' for people with eating disorders? No thanks. The Guardian. 27/9/2012. Accessed 2/6 2013 on http://www.theguardian.com/commentisfree $/ 2012 /$ sep/27/lady-gaga-body-revolutioneating-disorders

- Foucault, Michel (1975): Discipline and Punishment: The Birth of Prison. Penguin Books, London.

- Garland-Thomson, Rosemarie (2008): Extraordinary Bodies: Figuring Physical Disability in American Culture and Literature. Columbia University Press, New York.

- Halberstam, Jack (2010a): You Cannot Gaga Gaga. Accessed 28/12 2012 on: http://bullybloggers.wordpress.com $/ 2010 / 03 / 17 /$ you-cannot-gaga-gaga-by-jack-halberstam/.

- Halberstam, Jack (2010b): Calling All Angels Phoney Femininities in the Age of Gaga. No Longer in Exile: The Legacy and Future of Gender 
Studies at the New School Conference, New York, 27/3 2010. The New School, New York.

- Halberstam, Jack (2012a): Gaga Feminism: Sex, Gender, and the End of Normal. Beacon Press, Boston.

- Halberstam, Jack (2012b): Going Gaga: Scream, Shout, Lose Control. Accessed 30/4 2013 on: http://iaspm-us.net/jpms-online-popiaspm-ussounds-of-the-city-issue-jack-halberstam

- Halberstam, Jack (2013, in interview): Så funkar Lady Gaga-feminismen. Allt om Stockbolm.

21/5/2013. Accessed 15/6 2013 on

http://www.alltomstockholm.se/scenkultur/article4066174.aos

. Hall, Donald E. \& Jagose, Annemarie (2013): Introduction, in: Donald E. Hall \& Annemarie Jagose with Anndrea Bebell \& Susan Potter (eds.): The Routledge Queer Studies Reader. Routledge, New York.

- Kornowski, Liat (2013): Lady Gaga's Gold Wheelchair: Singer Recovers from Hip Surgery in a 24Karat 'Chariot'. Accessed 17/3 2014 on http://www.huffingtonpost.com/2013/03/13/1 ady-gagas-gold-wheelchair_n_2866671.html · McDougall, Kathleen (2006): 'Ag shame' and superheroes: stereotype and the signification of disability, in Brian Watermeyer, Leslie Swartz, Theresa Lorenzo, Marguerite Schneider, \& Mark Priestley (eds.): Disability and Social Change: A South African Agenda. HSRC Press, Cape Town. - McRuer, Robert (2006): Crip Theory: Cultural Signs of Queerness and Disability. New York University Press, New York.

- Richardson, Niall (2010): Transgressive Bodies: Representations in Film and Popular Culture. Ashgate, Surrey.
- Rogers, Chrissie (2010): But it's not all about the Sex: Mothering, Normalisation and Young Learning Disabled People, in: Disability \&́ Society 25/1.

- Shildrick, Margrit (2012): Critical Disability Studies: Rethinking the Concentions for the Age of Postmodernity, in Nick Watson, Carol Thomas, \& Allan Roulstone (eds.): Routledge Handbook of Disability Studies. Routledge, New York.

- Siebers, Tobin (2009): Disability Theory. University of Michigan Press, Ann Arbor.

. Schweik, Susan M. (2009): The Ugly Laws: Disability in Public. New York University Press, New York.

- Storey, John (2012): Cultural Theory and Popular Culture: An Introduction (sixth edition). Routledge, New York.

- Tregaskis, Claire (2002): Social Model Theory: the story so far..., in: Disability \& Society 17/4.

- Vaahtera, Elina (2012): Compulsory Able-bodiness and the Stigmatised Forms of Nondisability, in: Lambda Nordica 17/1-2.

- Von Glinow, Kiki (2011): Lady Gaga Rolls Out in Wheelchair for Sydney Performance, Gets Egged. Accessed 3/12 2013 on http://www.huffingtonpost.com/2011/07/13/lady-gaga-wheelchairegged-sydney-concert_n_897200.html - Waldholz, Chantal (2013): Lady Gaga Talk Weight Loss: I Love 'ArtPop' Because it Helped Me Lose 30 Pounds. Accessed 17/3 2014 on http://www.lifeandstylemag.com/posts/ladygaga-talks-weight-loss-i-love-artpop-because-ithelped-me-lose-30-pounds-33575 